\title{
Clarification and Stability Enhancement of Pear Juice using Loose Nanofiltration
}

\author{
V. Vivekanand ${ }^{1}$, M. lyer ${ }^{2}$, and S. Ajlouni ${ }^{3 *}$ \\ ${ }^{1}$ Technical Manager - Fats \& Whey Fonterra Australia Pty Ltd, 327 Ferntree Gully Road, Mt Waverley, Vic 3149, Australia \\ ${ }^{2}$ Program Manager Product Innovation Dairy Australia, Level 5, IBM Centre, 60 City Road, Southbank, Victoria, 3006, Australia \\ ${ }^{3}$ Department of Agriculture and Food Systems, Melbourne School of Land and Environment, The University of Melbourne, Parkville, Victoria 3010, Australia
}

\begin{abstract}
This research explored the possible application of loose Nanofiltration (NF) to enhance 19 stability and shelf life of pear juices. The results obtained from loose Nanofiltration of sulfite pre-treated (SPT) and sulphite un-treated pear juices (SUT) showed similar patterns of decline in flux rate and increase in volume concentration ratio (VCR) over time. The treated juice (loose NF permeate) showed a significant $(P<0.05)$ increase in lightness $\left(L^{*}\right)$, improvement from brownish tinge to clear light greenish tinge $\left(\mathrm{a}^{*}\right)$ and an improvement in overall colour difference $(\Delta \mathrm{Eab})$ values. Additionally, loose NF permeates from SPT and SUT were much clearer than the control as indicated by $87-91 \%$ improvement in percent adsorption. Loose NF permeates compared to control showed only a minor increase in the absorbance values when tested for stability at $80^{\circ} \mathrm{C}$. Such changes in the permeate characteristics indicated significant improvement juice quality. The retentate from loose NF revealed high sugar content $\left(17-18^{\circ}\right.$ Brix $)$, was dark brown in colour and contained more organic acids.
\end{abstract}

Keywords: Loose nanofiltration; Permeate; Retentate; Flux; Volume concentration ratio (VCR); Molecular weight cut off (MWCO)

\section{Introduction}

Membrane filtration in the fruit juice industry has grown from a novel approach into a reliable and economically attractive standard unit operation. Membrane processing has been used for concentrating, clarifying/fractionating and/or purifying fruit juices and for enhancing process efficiency and profitability. This technique has provided an excellent alternative for manufacturing high quality fruit juices under more hygienic conditions. Microfiltration (MF) \& ultrafiltration (UF) are cross flow filtration processes, which retain particles in a wide range from $10,000 \mathrm{Da}$ to $500,000 \mathrm{Da}$. MF and UF have been widely used for clarification of fruit juices such as pear and apple. However, studies suggest that UF juices are more susceptible to post bottling haze $(\mathrm{PBH})$ than traditionally clarified juices [1]. $\mathrm{PBH}$ is due to incomplete elimination of all potential haze precursors, products of polyphenol and protein interactions. This suggests that MF and UF, due to large pore size, are unable to retain all constituents and coloured compounds potentially responsible for imparting haze and brown colour formation. The use of smaller pore size or NF membranes may overcome this problem.

The borderline between UF and NF is not very distinct and overlaps in the range of 1000 to $5000 \mathrm{Da}$. Typically, Nanofiltration (NF) is a membrane separation process likely to reject molecules in the range of 100-5000 Da. This molecular weight cut off (MWCO) range is very important in the fruit juice processing industry because most of the polyphenolic compounds in this range usually permeate through the UF membrane and are often associated with defects like browning and haze formation. Membrane filtration with MWCO between 1000-5000 Da may be applied to retain majority of potential haze precursors, coloured organic compounds and at the same time allowing sugars and acids to pass through, which are major constituents of fruit juice. Figure 1 illustrated the characteristics of MF, UF, NF and Loose NF according to their MWCO.

NF applications have been developing over the years and in coming years may provide a convenient and economical way for decolourising and stabilising fruit juices (pear and apple juice). Generally, problems associated with NF include low flux rate, high rejection of sugars and requirement of a large membrane surface area. These problems have largely contributed to its limited application on a commercial scale. However, NF applications in the fruit juice industries are still in the developmental phase. A considerable amount of research needs to be done before juice manufacturers will accept NF as a suitable unit operation.

Recent advances in membrane manufacturing processes have resulted in the availability of thin film (polyamide) composite membranes (a thin film of polyamide is cast on a support layer, which is usually polysulfone) in the molecular weight cut off (MWCO) ranges of 1000-

\begin{tabular}{lcc|}
\hline Membrane Type & \multicolumn{1}{|l|}{ Pore Size $(\mu \mathrm{m})$} & $\begin{array}{l}\text { Molecular Weight } \\
\text { Cut-off (Da) }\end{array}$ \\
Loose NF & $10^{-3}-10^{-2}$ \\
NF & $10^{-3}-10^{-2}$ \\
UF & $10^{-2}-10^{-1}$ \\
MF & $10^{-1}-10^{1}$
\end{tabular}

Figure 1: A diagram comparing the characteristics of MF, UF, NF and Loose Nano-filtration according to molecular weight cut off ( $\mathrm{Da})$ and membrane pore size $(\mu \mathrm{m})$.

*Corresponding author: Said Ajlouni, Department of Agriculture and Food Sy stems, Melbourne School of Land and Environment, The University of Melbourne Parkville, Victoria 3010, Australia, Tel: (03) 83448620; Fax: (03) 83445037; E-mail: said@unimelb.edu.au

Received May 04, 2012; Accepted July 10, 2012; Published July 15, 2012

Citation: Vivekanand V, Iyer M, Ajlouni S (2012) Clarification and Stability Enhancement of Pear Juice using Loose Nanofiltration. J Food Process Techno 3:162. doi:10.4172/2157-7110.1000162

Copyright: (c) 2012 Vivekanand V, et al. This is an open-access article distributed under the terms of the Creative Commons Attribution License, which permits unrestricted use, distribution, and reproduction in any medium, provided the original author and source are credited. 
5000 MWCO. These thin film composite (TFC) polyamide membranes are also least tolerant to chlorine, which is generally specified in terms of "ppm-hours" [2]. Traditionally, UF membranes are manufactured by casting in a single layer, and these membranes have comparatively higher tolerance to chlorine. Therefore, to differentiate the membranes with these characteristics, the term "loose Nanofiltration" has been used in order to reflect a separate class NF membranes. These MWCO ranges may suit special applications to overcome post bottling haze (PBH) in the fruit juice processing industry.

In the dairy industry, spiral wound is the most popular membrane configuration. Spiral wound membranes are very economical because of low cost and small floor requirements compared to other designs. However, the spiral wound membrane design has not gained a significant acceptance by the fruit juice industry because pressing juices contains high levels of suspended solids that cause immediate fouling of spiral membranes. Furthermore, the presence of these suspended solids poses difficulties in cleaning of these spiral membranes.

For streams with high levels of suspended solids, tubular designs have been more widely used in the juice industry because they can handle fluids with high-suspended solids, have lower tendency to foul and can be cleaned easily. UF clarified pear juices contain little or no suspended matter and could be successfully used as a feed for a loose NF process.

Loose NF could be used as a secondary membrane process in spiral wound designs for decolourising and stabilising UF clarified fruit juices. Additionally, the improved design of the mesh spacers in spiral wound membranes has allowed handling of fluids with high soluble solids, and thus providing higher turbulence, lower tendency to foul and easier to clean membrane. The objective of the present study was to investigate the effect of loose NF on the quality characteristics of UF clarified pear juice.

\section{Materials and Methods}

\section{Pear juice}

UF clarified pear juice samples with and without pre-treatment with sulfite (oxidation of mash) and concentrated to $70^{\circ}$ Brix were kindly provided by a local fruit juice manufacturing company in Victoria. The concentrated pear juice samples that were sulfite pretreated (SPT)

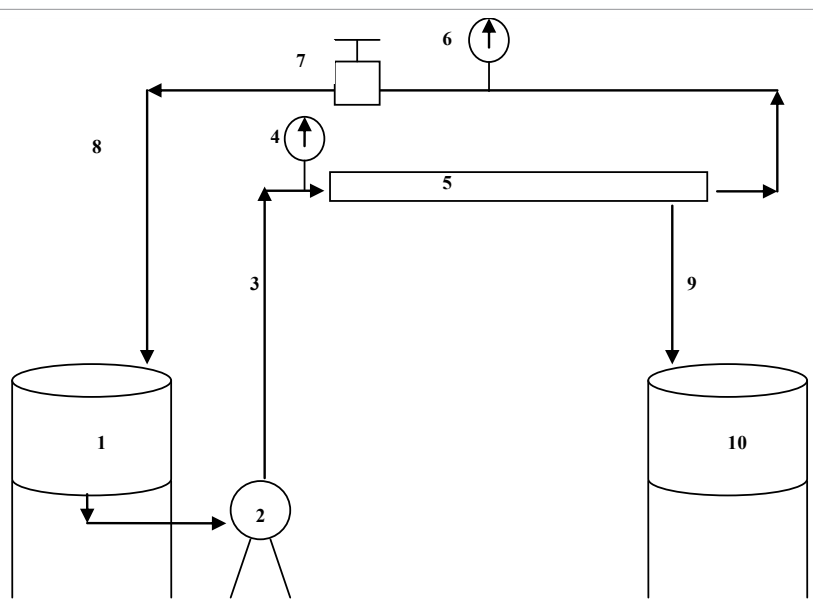

Figure 2: Schematic diagram of loose Nanofiltration pilot plant. [1: Feed tank; 2: Pump: 3: Feed; 4: Inlet pressure gauge; 5: Spiral wound membrane housing; 6: Outlet pressure gauge; 7: Back pressure valve; 8: Retentate; 9: Permeate; 10: Permeate tank]. were diluted to $13^{\circ} \mathrm{Brix}$ and $18^{\circ} \mathrm{Brix}$ and referred to as pear juice with sulfite (PJS) and partially concentrated pear juice with sulfite (PCPJS), respectively. The concentrated and sulphite untreated (SUT) pear juice was diluted to $13^{\circ}$ Brix only and referred to as pear juice without sulfite (PJWS). All these diluted pear juice samples were pumped through the loose NF pilot plant (Figure 2) in different batches, and permeate samples from each batch were collected.

\section{Loose nanofiltration system}

Loose Nanofiltration (NF) was performed in batches using a pilot plant (Filtration system, Getzville, NY, USA) fitted with a 5000 MWCO spiral wound membrane (GM,Thin film composite Polyamide membrane from Osmonics, area: $\left.0.353 \mathrm{~m}^{2}\right)$, with a chlorine tolerance of $1000 \mathrm{ppm}$ days and was operated at $50^{\circ} \mathrm{C}$ and $1240 \pm 5 \mathrm{kPa}$ average pressure (Figure 2). As a batch operation, permeate was collected in a separate tank and retentate was recirculated into the feed tank. Loose NF operation was terminated when the permeate flux reached 15-20 L/ $\mathrm{m}^{2} / \mathrm{hr}$ after $150 \mathrm{~min}$ of operation for PJS and PJWS and after $105 \mathrm{~min}$ for PCPJS. These trials were performed in triplicate for each type of juice (PJS, PJWS and PCPJS). Water and sucrose solution (12 ${ }^{\circ}$ Brix) were passed through the loose NF pilot plant in order to test the system operation parameters and both flux and VCR were evaluated.

\section{Cleaning of membranes}

Membrane cleaning was carried out using various cleaning solutions at $45-50^{\circ} \mathrm{C}$. Membranes were cleaned by flushing the system with water until it became clear ( 5 $136 \mathrm{~min})$, and circulating $0.3 \%$ of U 11 (Ultrasil 11, sodium hydroxide, Ecolab, Australia) for 20 minutes followed by water rinse until clear or the $\mathrm{pH}$ was 8 . This process was followed by circulating $0.6 \%$ of U 56 (Ultrasil 56, enzyme cleaner, Ecolab, Australia) for $25 \mathrm{~min}$ and then by water rinse until clear or the $\mathrm{pH}$ was 7. Sanitisation was carried out by circulating a solution of 0.3\% U MP (Ultrasil MP, acidic product, Ecolab, Australia) for $10 \mathrm{~min}$ followed by water rinse until clear or the $\mathrm{pH}$ was 7 . Finally $0.15 \%$ of $\mathrm{U}$ 11 was circulated again for $10 \mathrm{~min}$ and rinsed with water until clear or $\mathrm{pH}$ was 7-8 and the system was ready to be used again. Water flux of $150-175 \mathrm{~L} / \mathrm{m}^{2} / \mathrm{h}$ indicated that the system was clean and ready to be used again. In some of the experimental runs U 11 was replaced by Easy Advantage (Mildly alkaline detergent, Ecolab, Australia) to study any changes in the recovery of the original flux.

\section{Measurements, sampling and analysis}

Flux, inlet and outlet pressure and temperature on the loose NF system were recorded at $15 \mathrm{~min}$ intervals. Volume concentration ratio was calculated as the ratio of litres of feed to the litres of retentate at that particular time. Average pressure was recorded as a mean of the inlet and outlet pressure during loose nanofiltration. Measurements were recorded and samples were collected at 15 minute intervals until the nanofiltration was discontinued. Samples were stored at $-20^{\circ} \mathrm{C}$ for further analysis.

The membrane resistance (RM), total membrane resistance (RT) and irreversible fouling resistance (RF) were calculated using the following equations [3]:

$\mathrm{RM}=[\Delta \mathrm{PT} /(\eta \mathrm{J})]($ Equation 1$)$

where,

$\mathrm{RM}=$ Resistance due to membrane

$\Delta \mathrm{PT}=$ Average pressure 
$\eta=$ Viscosity of soft water

$\mathrm{J}=$ Water flux

$\mathrm{R}_{\mathrm{T}}=[\Delta \mathrm{PT} /(\eta \mathrm{J})]($ Equation 2$)$

where,

$\mathrm{RT}=$ Total resistance (using stabilized permeate flow)

$\Delta \mathrm{PT}=$ Average pressure

$\eta=$ Viscosity of permeate

$\mathrm{J}=$ Permeate flux

$\mathrm{R}_{\mathrm{F}}=[\{\Delta \mathrm{PT} /(\eta \mathrm{J})\}-\mathrm{RM}]($ Equation 3$)$

where,

$\mathrm{RF}=$ Irreversible fouling

$\mathrm{RM}=$ Resistance due to membrane

$\Delta \mathrm{PT}=$ Average pressure

$\eta=$ Viscosity of soft water

$J=$ Water flux (after fouling of membranes)

The samples were analysed for $\mathrm{pH}$, ${ }^{\circ}$ Brix, colour, clarity, titratable acidity as described by Vivekanand et al. [4,5] Sugars (sucrose, glucose, fructose, and sorbitol), organic acids (citric acid, malic acid and ascorbic acid) and phenolic compounds (arbutin, 5-hydroxy methyl furfural, chlorogenic acid, caffeic acid, p-coumaric acid and rutin) in pear juice samples were determined following the method of Vivekanand et al. [5] A Brookfield LVT viscometer at $60 \mathrm{rpm}$ with a UL adapter (Brookfield Engineering Laboratories Inc., Stoughton, MA, USA) was used to measure the viscosity of pear juice at $20^{\circ} \mathrm{C}$.

\section{Colour of loose NF permeate}

Colour characteristics of permeate were measured after diluting permeate to $12^{\circ} \mathrm{Brix}$, so that a comparison could be made at the same concentrations. Colour was measured directly and indirectly using a spectrophotometer (Shimadzu UV-1601, Japan) and a minolta chromameter,(Minolta, Model CR-300, Japan)

\section{Stability test}

Stability tests were conducted on all juice samples (permeates and concentrates). The juice concentrate samples were diluted to $12^{\circ} \mathrm{Brix}$ and $50 \mathrm{~mL}$ of this juice sample was heated to $80^{\circ} \mathrm{C}$ in a water bath (Laboratory water bath, Australia). Absorbance readings were recorded using a spectrophotometer (Shimadzu, Kyoto, Japan) at $425 \mathrm{~nm}$ after 0, $1,2,3,4$ and $5 \mathrm{~h}$ of heat treatment.

\section{Statistical analysis}

A randomized split plot design was used in the study and all external factors (juice samples, freezing, transportation and storage) were fixed. Each experiment was performed in triplicate, and results from analyses were recorded in duplicate (except for HPLC analysis, which was performed using samples from two experiments in duplicate). All the results obtained were statistically analyzed using Statistical Package for Social Science licensed through the University of Melbourne computer network. Variations between and within treatments were evaluated using analysis of variance. The means were separated using LSD at $95 \%$ confidence level.

\section{Results and Discussion}

\section{Water flux}

The water flux of the loose NF membrane at different average pressures and temperatures was determined (Figure 3). The flux increased steadily with pressure. Higher temperature favoured higher flux rate of water. It has been stipulated that higher velocity of water molecules at $50^{\circ} \mathrm{C}$ was mostly due to the high shift in hydrogen bonds within the water molecules thus reducing the viscosity.

Water flux is a measure of a membrane's permeability when the membrane is new and there are no fouling materials present on the surface of the membrane. Therefore, water flux provides a good estimate of the resistance offered by the membrane and therefore an indication of how well the membrane has been cleaned.

\section{Fluxes using sucrose solution}

Most fruit juices have a soluble solids concentration in the range of $12-22^{\circ}$ Brix, which are made up mainly of sugars [3] and to a small extent of organic acids. Permeate flow rates of sugar solutions provide an indication of the maximum attainable output of the filtered juice under ideal conditions i.e. no filtrable solids present. The effect of viscosity on the flux can also be estimated using such sugar solutions.

Sucrose solution $\left(12^{\circ}\right.$ Brix $)$ was initially passed through the membrane using a batch operation to study its effect on operating parameters (flux and volume concentration ratio) of the loose nanofiltration process. The $12^{\circ}$ Brix sugar concentration was chosen because it could represent the common average soluble solid concentration in most fruit juices. Table 1 shows the effect on flux, VCR and sugar rejection during membrane filtration. Loose NF of sucrose solution showed a sharp linear decrease in flux rate during the first 30 min, followed by gradual and less severe decline in flux over the last 90 min of the loose nanofiltration process. The VCR increased two fold in the first $30 \mathrm{~min}$ and four fold after $120 \mathrm{~min}$. The concentration of sugar increased to $13.5^{\circ} \mathrm{Brix}$ in the retentate during the first $15 \mathrm{~min}$

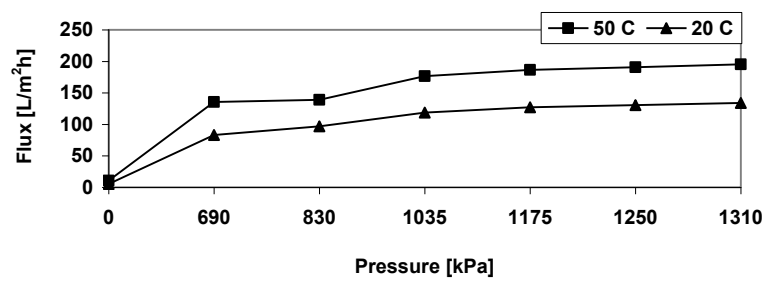

Figure 3: Changes in water flux at different temperatures and pressures. Results represent mean values of three runs.

\begin{tabular}{|c|c|c|c|c|}
\hline \multirow{2}{*}{$\begin{array}{c}\text { Time } \\
(\mathbf{m i n})\end{array}$} & $\begin{array}{c}\text { Permeate Flux } \\
(\mathbf{L} / \mathbf{m} / \mathbf{h r})\end{array}$ & VCR & \multicolumn{2}{|c|}{ Brix } \\
\hline Start & $135.7 \pm 0.00$ & $1.0 \pm 0.00$ & $12 \pm 0.00$ & $12 \pm 0.00$ \\
\hline $\mathbf{1 5}$ & $118.7 \pm 0.00$ & $1.5 \pm 0.03$ & $12 \pm 0.00$ & $13.5 \pm 0.00$ \\
\hline $\mathbf{3 0}$ & $101.8 \pm 0.00$ & $2.0 \pm 0.00$ & $12 \pm 0.00$ & $13.5 \pm 0.00$ \\
\hline $\mathbf{4 5}$ & $101.8 \pm 0.00$ & $2.4 \pm 0.00$ & $12 \pm 0.00$ & $13.5 \pm 0.00$ \\
\hline $\mathbf{6 0}$ & $93.3 \pm 0.00$ & $2.8 \pm 0.00$ & $12 \pm 0.00$ & $13.5 \pm 0.00$ \\
\hline $\mathbf{7 5}$ & $93.3 \pm 0.00$ & $3.2 \pm 0.00$ & $12 \pm 0.00$ & $13.5 \pm 0.00$ \\
\hline $\mathbf{9 0}$ & $84.8 \pm 0.00$ & $3.5 \pm 0.00$ & $12 \pm 0.00$ & $13.5 \pm 0.00$ \\
\hline $\mathbf{1 0 5}$ & $84.8 \pm 0.00$ & $3.8 \pm 0.00$ & $12 \pm 0.00$ & $13.5 \pm 0.00$ \\
\hline $\mathbf{1 2 0}$ & $76.3 \pm 0.00$ & $4.0 \pm 0.00$ & $12 \pm 0.00$ & $13.5 \pm 0.00$ \\
\hline
\end{tabular}

Table 1: Loose Nanofiltration of sucrose solution $\left(12^{\circ} \mathrm{Brix}\right)$ at an average pressure of $1241 \mathrm{kPa}$. Results represent mean values of three runs \pm SD. 
and remained constant thereafter. These results suggest that during the initial $30 \mathrm{~min}$, maximum fouling of the membrane occurred and high osmotic pressure offered by the increase in VCR and ${ }^{\circ}$ Brix value (contributed by the total soluble solids). The decline in flux may be attributed to the sucrose membrane interactions and concentration polarisation at the membrane surface, thereby increasing the overall resistance and finally leading to membranes fouling.

\section{Pear juice processing}

Flux: The starting flux rate of PCPJS $\left(18^{\circ} \mathrm{Brix}\right)$ was approximately 2 times lower than PJS $\left(13^{\circ}\right.$ Brix $)$ and PJWS $\left(13^{\circ}\right.$ Brix $)$. However, data revealed that the permeate fluxes for PJS and PJWS were significantly higher $(\mathrm{P}<0.05)$ than that in PCPJS throughout the process (Figure 4). This difference in flux rate was mostly due to the higher amount of total solids and higher viscosity in the partially concentrated pear juice with sulfite (PCPJS). Permeate flux of PJS and PJWS was found to be approximately 2 times lower than the flux rate recorded for sucrose solution and approximately 3 times lower than water flux recorded at the same temperature $\left(50^{\circ} \mathrm{C}\right)$. A similar trend was reported previously by Padilla-Zakour and McLellan [3]. These results indicated that drastic reduction in permeation rate was mostly due to high viscosity in the PCPJS feed, caused by high total soluble solids, which may have partially contributed to high osmotic pressure during the loose NF process of PCPJS (Figure 4). It was also noted from the same data that there was a sharp decline in flux rate in the first $30 \mathrm{~min}$ of the loose NF process for all three types of juice processed (PJS, PJWS and PCPJS). A similar pattern was also observed during loose NF of sucrose solution, whereas, the flux rate gradually declined after the initial period. It should be noted that juices used during this experiment were clear (without any suspended solids) or other fibrous materials. This makes it evident that the recorded decrease in flux rate during loose NF was mostly controlled by the amount of soluble solids and the osmotic pressure created by these molecules (sugars, organic acids). Additionally, Wagner [6] suggested that colour substances (tannins and phenolic compounds) found in pear juice have a tendency to form chemical bonds with aromatic rings present in the polyamide membranes and thus leading to severe fouling of the membrane. Table 2 summarises the total resistance offered by the membrane, the irreversible fouling at

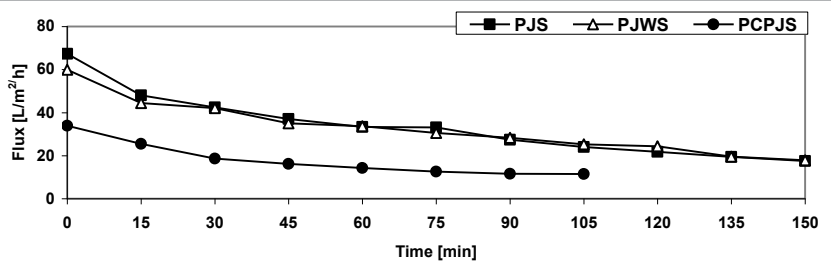

Figure 4: Changes in flux over time. Results represent mean values of three runs.

\begin{tabular}{|l|l|l|l|}
\hline Feed & $\begin{array}{l}\text { Total resistance } \\
(\mathbf{R T})^{* *}\left(\mathbf{3 6} \mathbf{\times} \mathbf{1 0}^{-11} \mathbf{~}^{-1}\right)\end{array}$ & $\begin{array}{l}\text { Irreversible fouling } \\
\mathbf{( R F})^{\star *}\left(\mathbf{3 6} \mathbf{~} \mathbf{1 0}^{-11} \mathbf{~ m}^{-1}\right)\end{array}$ & $\begin{array}{l}\text { Viscosity of } \\
\text { Permeate }(\mathbf{c p s})\end{array}$ \\
\hline Water & $6.78 \pm 0.00$ & - & $0.96 \pm 0.00$ \\
\hline Sucrose solution & $9.55 \pm 0.00$ & $2.12 \pm 0.00$ & $0.96 \pm 0.00$ \\
\hline PJS & $74.00 \pm 0.00$ & $3.73 \pm 0.00$ & $0.96 \pm 0.00$ \\
\hline PJWS & $72.59 \pm 0.00$ & $5.93 \pm 0.00$ & $0.96 \pm 0.00$ \\
\hline PCPJS & $102.26 \pm 0.00$ & $4.89 \pm 0.00$ & $1.06 \pm 0.00$ \\
\hline
\end{tabular}

${ }^{*} \mathrm{RM}$ : Membrane resistance

${ }^{* *} \mathrm{RT}$ : Total membrane resistance

${ }^{* *} \mathrm{RF}$ : Irreversible fouling resistance

Table 2: Resistance offered by the loose NF membrane using different feed solutions ( ${ }^{*} \mathrm{RM}$ : $6.78 \times 36 \times 10^{-11} \mathrm{~m}^{-1}$ ). Results represent mean value of three runs $\pm \mathrm{SD}$.

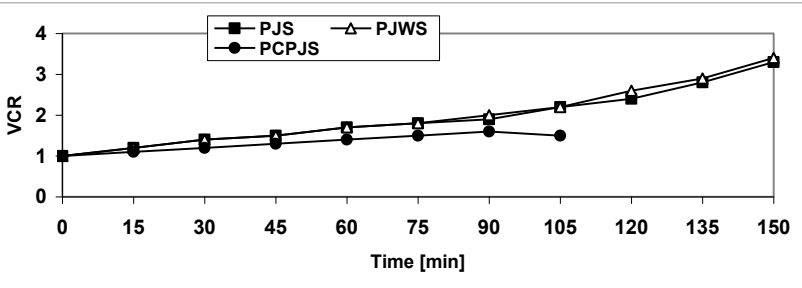

Figure 5: Relative changes in VCR with time. Results represent mean values of three runs and bars indicate standard deviation. Bars are not clear due to very small standard deviation.

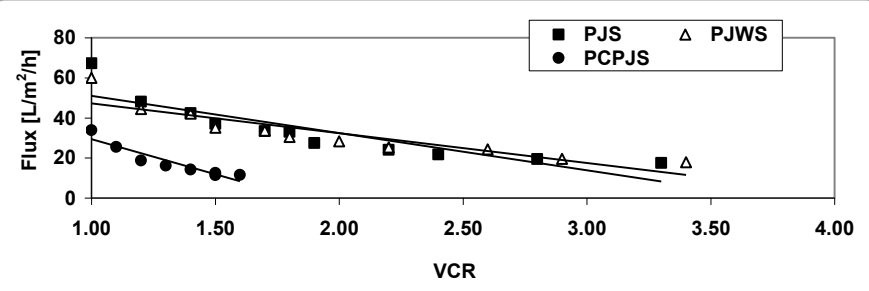

Figure 6: Variation in flux at different VCR. Results represent mean values of three runs.

the end of the loose NF process and the viscosity of the different feed solutions used during experiments. It was noted that water offered the least membrane resistance, whereas sucrose solution showed slightly higher resistance. PJS, PJWS and PCPJS showed higher RT (Table 2) in comparison with $\operatorname{Rf}(P<0.05)$, which suggests an extreme case of concentration polarisation in addition to fouling of the membrane.

Volume concentration ratio: A gradual increase in VCR for PJS and PJWS was recorded throughout the loose NF process (Figure 5). The VCR attained by PJS and PJWS showed a similar trend throughout the loose NF process. The VCR achieved by PCPJS was significantly $(P$ $<0.05)$ lower than the VCR achieved by PJS and PJWS when compared after 105 min of processing time.

VCR was also compared with the flux rate of these juices (PJS, PJWS and PCPJS) as shown in figure 6. A similar pattern was noted for all juices. There was a linear decrease in the flux rate with an increase in the VCR as explained previously. It was also observed that PJS and PJWS showed a significantly higher $(P<0.05)$ flux rate compared to PCPJS (Figure 5 and 6). These results are in agreement with those reported by Heatherbell et al. [7], Kirk et al. [8], Yu and Chiang [9], Girard and Fukumoto [10], Vivekanand et al.[4,5].

Cleaning of the membranes: The membrane was cleaned as described previously (section 2.3). The U 11 was replaced by Easi Advantage in some experiments because it has been designed to clean membranes fouled with polyphenolics and coloured compounds. It was very difficult to get the original water flux through the loose NF membrane after processing PCPJS. Even cleaning using Easi Advantage chemicals, which are especially used for cleaning membranes fouled with tannins and coloured organic compounds, did not improve the water flux. This suggested that the membrane may have been irreversibly fouled by the coloured organic compounds from PCPJS.

Colour of loose NF permeates: As shown in Table 3 improvement in colour was observed in all permeate (PJS, PJWS and PCPJS) samples. The colour characteristics looked optically clear when visually examined. It was noted that $L^{*}$ values of permeates from loose NF were significantly $(P<0.05)$ improved. The degree of lightness in PJS, PJWS and PCPJS was significantly better than that in the control. However, 


\begin{tabular}{|l|l|l|l|l|l|}
\hline Permeate & Absorbance & Clarity & $\mathbf{L}^{*}$ & $\mathbf{a}^{*}$ & $\Delta$ Eab \\
\hline $\begin{array}{l}\text { Control } \\
\text { (Sulfurized) }\end{array}$ & $0.3 \pm 0.03$ & $0.0 \pm 0.00$ & $-31.9 \pm 1.02$ & $-5.3 \pm 1.9$ & $42.1 \pm 0.44$ \\
\hline $\begin{array}{l}\text { Control } \\
\text { (Unsulfurized) }\end{array}$ & $0.4 \pm 0.02$ & $0.1 \pm 0.00$ & $-33.9 \pm 0.52$ & $-5.4 \pm 0.1$ & $44.3 \pm 0.51$ \\
\hline PJS & $0.1 \pm 0.00$ & $0.0 \pm 0.00$ & $-22.9 \pm 1.29$ & $-12.6 \pm 1.01$ & $33.4 \pm 0.52$ \\
\hline PJWS & $0.0 \pm 0.00$ & $0.0 \pm 0.00$ & $-22.0 \pm 0.06$ & $-14.0 \pm 0.11$ & $33.6 \pm 0.19$ \\
\hline PCPJS & $0.1 \pm 0.01$ & $0.0 \pm 0.00$ & $-22.1 \pm 0.51$ & $-12.75 \pm 0.42$ & $33.5 \pm 0.36$ \\
\hline
\end{tabular}

Table 3: Colour characteristics of loose NF permeate. Results represent mean values of three runs \pm standard deviation.

\begin{tabular}{|l|l|l|l|l|l|l|}
\hline Permeate & Arbutin & $\begin{array}{l}\text { Chloro- } \\
\text { genic acid }\end{array}$ & $\begin{array}{l}\text { Caffeic } \\
\text { acid }\end{array}$ & $\begin{array}{l}\text { p-Cou- } \\
\text { maric } \\
\text { acid }\end{array}$ & Rutin & HMF \\
\hline $\begin{array}{l}\text { Control } \\
\text { (Sulfu- } \\
\text { rized) }\end{array}$ & $23.5 \pm 0.01$ & $91.7 \pm 0.03$ & $14.9 \pm 0.00$ & $5.0 \pm 0.00$ & $9.8 \pm 0.00$ & $0.0 \pm 0.00$ \\
\hline $\begin{array}{l}\text { Control } \\
\text { (Unsul- } \\
\text { furized) }\end{array}$ & $35.9 \pm 0.01$ & $43.8 \pm 0.02$ & $11.6 \pm 0.01$ & $2.9 \pm 0.00$ & $4.4 \pm 0.00$ & $0.0 \pm 0.00$ \\
\hline PJS & $3.3 \pm 0.02$ & $19.2 \pm 0.02$ & $1.4 \pm 0.01$ & $0.9 \pm 0.00$ & $5.9 \pm 0.00$ & $0.0 \pm 0.00$ \\
\hline PJWS & $4.6 \pm 0.03$ & $16.7 \pm 0.01$ & $0.4 \pm 0.00$ & $0.3 \pm 0.00$ & $0.4 \pm 0.00$ & $0.0 \pm 0.00$ \\
\hline PCPJS & $7.0 \pm 0.03$ & $19.9 \pm 0.02$ & $0.4 \pm 0.00$ & $0.8 \pm 0.00$ & $4.4 \pm 0.02$ & $0.0 \pm 0.00$ \\
\hline
\end{tabular}

Table 4: Polyphenolic content (mg/L) in loose NF permeates. Results represent mean values of four measurements from two runs \pm standard deviation.

there were no significant differences $(P>0.05)$ between the three types of permeate.

Similarly, the degree of redness to greenness was also reported in terms of $a^{*}$ value $\left(+a^{*} 315=\right.$ red and $-a^{*}=$ green $)$. There was $a$ significant improvement $(P<0.05)$ in the degree of 316 greenness in all permeates (PJS, PJWS and PCPJS) compared to the control (Table 3). No significant differences $(P>0.05)$ in $\mathrm{a}^{*}$ values were observed between these permeates.

The colour difference values $(\triangle \mathrm{Eab})$ were in agreement with $\mathrm{L}^{*}$ and $\mathrm{a}^{*}$ values (Table 3$)$ and revealed significant $(P<0.05)$ improvement in the overall colour of various permeates (PJS, PJWS and PCPJS) compared to their controls.

Clarity was measured also as absorbance at $650 \mathrm{~nm}$ (Table 3), and all permeates (PJS, PJWS and PCPJS) were found to be $100 \%$ clear when compared with their control samples. There was a significant reduction $(P<0.05)$ in the absorbance noted for all the three different feeds used (PJS, PJWS and PCPJS). During loose NF, absorbance was improved (reduced value) by $85 \%$ and $76 \%$ for PJS and PCPJS, respectively in comparison to the control. However, loose NF of PJWS showed an improvement in absorbance by $90 \%$ compared to control. These observations may suggest that loose NF can improve the colour of un-sulfurized fruit juices much better than juices treated with sulfur, because pear juice without sulfur (PJWS) had darker original colour in the absence of sulfur (Table 3 ).

Our data showed a significant $(P<0.05)$ reduction in the concentration of all the polyphenolic compounds measured in all permeates (PJS, PJWS and PCPJS) as compared to the controls (Table 4). It was also noted that nanofiltered PJWS had comparatively smaller amounts of polyphenolic compounds except arbutin when compared to nanofiltered PJS. These results indicated that UF permeate obtained from oxidised mash would give a better quality product compared to the one treated with sulfites. Additionally, this suggested that loose NF was able to retain most of the polyphenolic and coloured organic compounds and hence helped in the manufacture of a very light coloured pear juice with negligible amount of organic coloured compound and phenolic compounds.

pH and titratable acidity in loose NF permeate: No significant $(P$ $>0.05)$ changes in $\mathrm{pH}$ or titratable acidity were detected in any pear juice samples (PJS, PJWS and PCPJS) after loose NF (Table 5).

Malic, citric and ascorbic acids were quantified using HPLC technique. It was interesting to note that there was only a minor reduction in the content of malic acid whereas there was a significant decrease $(P<0.05)$ in the amount of citric acid in the nanofiltered PJS. The amounts of citric acid in the control sample of PJWS was significantly lower $(P<0.05)$ than control sample of pear juice with sulfur (PJS), which may be possibly due to rapid oxidation of citric acid during oxidation of mash and retention of these during UF of the original samples.

Ascorbic acid was found to be significantly $(P<0.05)$ reduced in all the permeate samples from loose NF of PJS, PJWS and PCPJS. This suggested that reduction in ascorbic acid content was mainly due to rapid oxidation during the loose NF process.

Sugars and minerals in loose NF permeate: Permeation of sugars is one of the important factors for the viability of the loose NF process in the fruit juice processing industry. Table 6 summarizes the different sugars measured using HPLC, and ${ }^{\circ}$ Brix values recorded on a refractometer. There was a significant $(P<0.05)$ reduction in the fructose and sucrose content in PJS and PJWS compared to the feed (control). However, no significant $(P>0.05)$ changes were noted for

\begin{tabular}{|l|l|l|l|l|l|}
\hline Permeate & pH & TA (\%) & $\begin{array}{l}\text { Malic acid } \\
(\%)\end{array}$ & $\begin{array}{l}\text { Citric acid } \\
(\%)\end{array}$ & $\begin{array}{l}\text { Ascorbic acid } \\
\text { (mg/100mL) }\end{array}$ \\
\hline $\begin{array}{l}\text { Control (Sulfu- } \\
\text { rized) }\end{array}$ & $3.9 \pm 0.02$ & $0.4 \pm 0.00$ & $0.5 \pm 0.02$ & $0.22 \pm 0.01$ & $6.4 \pm 0.17$ \\
\hline $\begin{array}{l}\text { Control (Un- } \\
\text { sulfurized) }\end{array}$ & $3.9 \pm 0.01$ & $0.3 \pm 0.00$ & $0.5 \pm 0.01$ & $0.02 \pm 0.00$ & $5.0 \pm 0.15$ \\
\hline PJS & $3.9 \pm 0.0$ & $0.3 \pm 0.00$ & $0.4 \pm 0.06$ & $0.04 \pm 0.00$ & $2.8 \pm 0.42$ \\
\hline PJWS & $3.9 \pm 0.02$ & $0.3 \pm 0.00$ & $0.5 \pm 0.04$ & $0.01 \pm 0.00$ & $2.9 \pm 0.63$ \\
\hline PCPJS & $3.9 \pm 0.00$ & $0.4 \pm 0.00$ & $0.6 \pm 0.04$ & $0.04 \pm 0.00$ & $2.4 \pm 0.61$ \\
\hline
\end{tabular}

Table 5: pH, titratable acidity and organic acid content in loose NF permeate. Results represent mean values of three runs \pm standard deviation.

\begin{tabular}{|c|c|c|c|c|c|c|c|c|c|c|}
\hline Permeate & \multicolumn{2}{|c|}{ Sucrose } & \multicolumn{2}{|c|}{ Glucose } & \multicolumn{2}{|c|}{ Fructose } & \multicolumn{2}{|c|}{ Sorbitol } & Total & oBrix \\
\hline $\begin{array}{l}\text { Control } \\
\text { ( S u I f u - } \\
\text { rized) }\end{array}$ & \multicolumn{2}{|c|}{$0.71 \pm 0.01$} & \multicolumn{2}{|c|}{$2.20 \pm 0.03$} & \multicolumn{2}{|c|}{$9.28 \pm 0.12$} & \multicolumn{2}{|c|}{$2.54 \pm 0.02$} & 14.73 & $13.00 \pm 0.00$ \\
\hline $\begin{array}{l}\text { Control } \\
\text { ( U n s u I - } \\
\text { furized) }\end{array}$ & \multicolumn{2}{|c|}{$0.65 \pm 0.00$} & \multicolumn{2}{|c|}{$2.67 \pm 0.02$} & \multicolumn{2}{|c|}{$9.78 \pm 0.08$} & \multicolumn{2}{|c|}{$2.56 \pm 0.03$} & 15.66 & $13.00 \pm 0.00$ \\
\hline PJS & \multicolumn{2}{|c|}{$0.31 \pm 0.01$} & \multicolumn{2}{|c|}{$2.12 \pm 0.02$} & \multicolumn{2}{|c|}{$6.91 \pm 0.03$} & \multicolumn{2}{|c|}{$2.30 \pm 0.04$} & 11.64 & 11. \\
\hline PJWS & \multicolumn{2}{|c|}{$0.27 \pm 0.01$} & \multicolumn{2}{|c|}{$2.74 \pm 0.03$} & \multicolumn{2}{|c|}{$6.64 \pm 0.02$} & \multicolumn{2}{|c|}{$2.18 \pm 0.17$} & 11.83 & $12.75 \pm 0.30$ \\
\hline PCPJS & \multicolumn{2}{|c|}{$0.27 \pm 0.02$} & \multicolumn{2}{|c|}{$2.35 \pm 0.02$} & 7.32 & $2 \pm 0.03$ & \multicolumn{2}{|c|}{$2.16 \pm 0.04$} & 12.00 & 15.1 \\
\hline \multicolumn{11}{|c|}{$\begin{array}{l}\text { Table 6: Sugar content }(\%) \text { in loose NF permeates. Results represent the mean of } \\
\text { four measurements from two runs } \pm \text { standard deviation. }\end{array}$} \\
\hline \multicolumn{2}{|l|}{ Permeate } & \multicolumn{2}{|l|}{$\mathrm{Cu}$} & \multicolumn{2}{|l|}{$\mathrm{Fe}$} & \multicolumn{2}{|l|}{$\mathrm{Na}$} & \multicolumn{2}{|l|}{$\mathrm{Ca}$} & K \\
\hline \multicolumn{2}{|c|}{$\begin{array}{l}\text { Control } \\
\text { (Sulfurized) }\end{array}$} & \multicolumn{2}{|c|}{$0.34 \pm 0.05$} & \multicolumn{2}{|c|}{$0.49 \pm 0.06$} & \multicolumn{2}{|c|}{$83.72 \pm 0.02$} & \multicolumn{2}{|c|}{$19.75 \pm 0.08$} & $1277 \pm 0.07$ \\
\hline \multicolumn{2}{|c|}{$\begin{array}{l}\text { Control } \\
\text { (Unsulfurized) }\end{array}$} & \multicolumn{2}{|c|}{$0.39 \pm 0.08$} & \multicolumn{2}{|c|}{$0.66 \pm 0.07$} & \multicolumn{2}{|c|}{$37.44 \pm 0.02$} & $22.85 \pm$ & \pm 0.05 & $1119.8 \pm 0.07$ \\
\hline PJS & & $0.25 \pm 0$ & 0.04 & $0.05 \pm 0$ & 0.04 & $80.9 \pm 0$ & 0.09 & $9.05 \pm c$ & 0.06 & $1016.9 \pm 0.08$ \\
\hline PJWS & & $0.24 \pm 0$ & 0.07 & $0.33 \pm 0$ & 0.06 & $30.98 \pm$ & 0.08 & $5.9 \pm 0$. & & $1065.6 \pm 0.04$ \\
\hline
\end{tabular}

Table 7: Mineral content (mg/L) in loose NF permeate. Results represent mean values of three runs \pm standard deviation. 
glucose and sorbitol contents. There was a reduction of $10 \%, 8 \%$ and $13 \%$ in the $364{ }^{\circ} \mathrm{Brix}$ content of the PJS, PJWS and PCPJS, respectively.

Loose NF permeates (PJS and PJWS) showed significant $(P<0.05)$ reduction in iron and calcium content, whereas insignificant $(P>0.05)$ changes were noted for copper, sodium and potassium (Table 7).

Colour of loose NF retentate: Visual examination of the retentate from all three trials revealed dark brown colour and viscous texture. The retentate had a very high amount of coloured compounds and therefore had a high absorbance and dark colour (Table 8). Dark colour of the retentate was mainly due to concentration of coloured compounds.

pH and titratable acidity in loose NF retentate: Loose NF retentate samples (Table 9) showed a minor decrease in $\mathrm{pH}$ value and a significant $(P<0.05)$ increase in titratable acidity when compared with their control samples (Table 5). This was mostly due to the higher concentration of the organic acids in the retentate.

The ${ }^{\circ}$ Brix values of the loose NF retentate of pear juice with sulfur, without sulfur, and partially concentrated pear juice with sulfur were found to be approximately $18-20^{\circ}$ Brix. These figures suggest that the retentate was very rich in sugars, titratable acids and coloured organic compounds. The retentate could be easily recycled during the preliminary UF process, to recover most of remaining sugars and acids and therefore maximize the recovery of these important constituents.

\section{Conclusions}

The results revealed no significant $(P>0.05)$ differences in the flux rate and VCR trend over time of both pear juices (PJS and PJWS). The loose NF permeate showed a significant $(P<0.05)$ improvement in colour as indicated by the increase in lightness $\left(L^{*}\right)$, improvement from brownish tinge to clear light greenish tinge $\left(\mathrm{a}^{*}\right)$ and an improvement in overall colour difference $(\triangle \mathrm{Eab})$ values. The degree of lightness in PJS, PJWS and PCPJS were significantly better than that in the control. However, there were no significant differences $(P>0.05)$ between the three types of permeate. Additionally loose NF permeates from pear juice with sulfur (PJS) and without sulfur (PJWS) were clear as indicated by $85-90 \%$ reduction in $\%$ adsorption. Loose NF permeates from PJS and PJWS showed only $10 \%$ and $7.0 \%$ reduction in the ${ }^{\circ}$ Brix content, respectively. There were no significant $(P>0.05)$ changes in the $\mathrm{pH}$ values; however, there was minor reduction in the titratable acidity.
The decline in titratable acidity could be attributed to the decrease in both, citric and ascorbic acids of the permeate as our results revealed. Permeate stability during storage at $20^{\circ} \mathrm{C}$ showed a minor increase in the absorbance values when tested for stability at $80^{\circ} \mathrm{C}$. Consequently, it was concluded that loose NF could improve quality of pear juice permeate. The retentate from loose NF was dark brown in colour and had more sugar content (18-20 Brix) and more organic acids, which could be reused during clarification process (UF) to recover more of these sugars and organic acids.

\section{Acknowledgement}

Grateful acknowledgement is extended to Mr. Tri Q. Huynh from Osmonics, Minnesota, USA for supplying spiral membrane, Mr. Brandon Moore from Ecolab, Australia for supplying all the cleaning and sanitation chemicals for the loose Nanofiltration membrane experiment and $\mathrm{Mr}$ Joe Pelle from Victoria University for assistance during analysis on atomic adsorption unit at Victoria University, Werribee campus

\section{References}

1. Nagel CW, Schobinger U (1985) Investigation of the Origin of Turbidity in Ultrafiltered Apple and Pear Juice Concentrate. Confructa Studien 26: 16.

2. Cheryan M (1998) Ultrafiltration and Microfiltration Handbook. Technomic Publishing Co. Lancaster.

3. Padilla-Zakour OI, McLellan MR (1993) Optimization and Modelling of Apple Juice Cross Flow Micro-filtration with a Ceramic Membrane. J Food Sci 58 : 369-374

4. Vivekanand V, lyer M, Ajlouni S (2001) Ultrafiltration of Partially Concentrated Pear Juice. Fruit Processing 11: 256-263.

5. Vivekanand, Ajlouni S, Iyer M (2003) Quality Enhancement of UF Clarified Pea Juice using Adsorbent and Weak Base Resins at Different Temperatures. J Food Sci 68: 333-338.

6. Wagner J (2001) Membrane Filtration Handbook. Osmonics Inc USA

7. Heatherbell DA, Short JL, Strubi P (1977) Apple Juice Clarification by Ultrafiltration. Confructa Studien 22: 157.

8. Kirk DE, Montgomery MW, Kortekaas MG (1983) Clarification of Pear Juice by Hollow Fiber Ultrafiltration. J Food Sci 48: 1663-1667.

9. Yu ZR, Chiang BH (1986) Passion Fruit Juice Concentration by Ultrafiltration and Evaporation. J Food Sci 51: 1501-1505

10. Girard B, Fukumoto LR (2000) Membrane Processing of Fruit Juices and Beverages: A Review. Crit Rev Biotechnol 20: 109-75.

\begin{tabular}{|l|l|l|l|l|l|}
\hline Retentate & Abs & Clarity & $\mathbf{L}^{*}$ & $\mathbf{a}^{*}$ & $\Delta$ Eab \\
\hline $\begin{array}{l}\text { Control } \\
\text { (Sulfurized) }\end{array}$ & $0.3 \pm 0.03$ & $0.0 \pm 0.00$ & $-31.9 \pm 1.02$ & $-5.3 \pm 1.9$ & $42.1 \pm 0.44$ \\
\hline $\begin{array}{l}\text { Control } \\
\text { (Unsulfurized) }\end{array}$ & $0.4 \pm 0.02$ & $0.1 \pm 0.00$ & $-33.9 \pm 0.52$ & $-5.4 \pm 0.1$ & $44.3 \pm 0.51$ \\
\hline PJS & $0.89 \pm 0.13$ & $0.11 \pm 0.01$ & $-36.53 \pm 0.52$ & $-3.96 \pm 0.83$ & $49.50 \pm 0.79$ \\
\hline PJWS & $1.34 \pm 0.06$ & $0.13 \pm 0.01$ & $-37.12 \pm 0.06$ & $-4.66 \pm 0.05$ & $50.46 \pm 0.40$ \\
\hline PCPJS & $0.71 \pm 0.03$ & $0.09 \pm 0.01$ & $-35.5 \pm 0.13$ & $-2.57 \pm 0.14$ & $47.88 \pm 0.31$ \\
\hline
\end{tabular}

Table 8: Colour characteristics of loose NF retentate. Results represent mean values of three runs \pm standard deviations.

\begin{tabular}{|c|c|c|}
\hline Retentate & pH & TA \\
\hline Control (Sulfurized) & $3.90 \pm 0.02$ & $0.4 \pm 0.00$ \\
\hline $\begin{array}{c}\text { Control } \\
\text { (Unsulfurized) }\end{array}$ & $3.90 \pm 0.01$ & $0.3 \pm 0.00$ \\
\hline PJS & $3.84 \pm 0.02$ & $0.74 \pm 0.00$ \\
\hline PJWS & $3.76 \pm 0.01$ & $0.74 \pm 0.00$ \\
\hline PCPJS & $3.86 \pm 0.00$ & $1.07 \pm 0.00$ \\
\hline
\end{tabular}

Table 9: $\mathrm{pH}$ and titratable acidity (TA) of loose NF retentate. Results represent mean values of three runs \pm standard deviation. 